\title{
CONSTRUÇÃO DE SUJEITOS CORPORAIS E PRÁTICAS ANTIRRACISTAS NA ESCOLA LIVRE DE DANÇA DA MARÉ
}

\author{
Gabriel Ramon Ferreira Limai \\ Silvia Camara Soter da Silveira ${ }^{\text {ii }}$
}

\begin{abstract}
Resumo: Este artigo busca refletir sobre a constituição de sujeitos corporais a partir de relatos de um professor e de estudantes da Escola Livre de Dança da Maré — ELDM sobre suas interações com as forças de segurança pública do Estado. Apoia-se nos pressupostos de Kilomba (2019) e de Fanon (2008) para o reconhecimento das marcas infligidas pelo racismo cotidiano na formação do esquema corporal de indivíduos negros no território da Maré, no Rio de Janeiro. Constata-se que a criação de espaços para a reflexão sobre questões como o racismo e a violência, nos processos pedagógicos da ELDM, têm sido estratégias efetivas de educação antirracista para a formação corporal de indivíduos mais conscientes e críticos em relação às questões raciais e sociais às quais estão submetidos.
\end{abstract}

Palavras-chave: Dança; Corpo; Racismo; Educação.

\section{CONSTITUTION OF BODILY SUBJECTS AND ANTIRACIST PRACTICES AT ESCOLA LIVRE DE DANÇA DA MARÉ}

Summary: Thispaperattempts to reflectontheconstitutionofbodilysubjectsbasedonaccountsby a teacherand a fewstudentsat Escola Livre de Dança da Maré - ELDM (the Maré Dance Free School) abouttheirinteractionswithStatepolice forces. It'ssupportedbytheworksofKilomba (2019) andFanon (2008) to recognizemarksinflictedbydailyracism in shapingthephysicalstructureofBlackindividuals in the Maré territory, in Rio de Janeiro. Findings show thatthecreationofspaces for reflectionaboutissuesrelating to racismandviolence in ELDM pedagogical processes hasbeenaneffectivestrategy for anti-racisteducationand for composingindividual bodieswhich are more consciousandcriticalof racial and social issues to whichthey'resubjected.

Keywords: Dance; Body; Racism; Education.

\section{Introdução}

Este artigo busca refletir sobre o impacto de ações de forças do Estado no Rio de Janeiro, neste caso da polícia militar em sua atuação na Maré, na constituição de sujeitos corporais. Em uma cidade onde o corpo preto e favelado vem sendo sistematicamente alvo da violência, utilizaremos relatos de um professor e de estudantes da Escola Livre de Dança da 
Maré - ELDM para pensar como se dá a educação dos corpos nas interações com as forças do Estado em territórios como a Maré.

Os aportes de Kilomba (2019) e de Fanon (2008) serviram de guia para o reconhecimento das marcas infligidas pelo racismo cotidiano (KILOMBA, 2019) na formação do esquema corporal de indivíduos negros (FANON, 2008). Suas perspectivas reforçam a urgência em se levar em conta a vivência corporal de sujeitos negros para a criação de uma nova epistemologia no meio acadêmico como um todo, e para a formação inicial e continuada de professores, em específico (GOMES; SILVA, 2011).

$\mathrm{Na}$ aposta de que a vivência corporal é ao mesmo tempo única e fundante, já que nela se entrelaçam aspectos distintos da identidade do pesquisador e do sujeito que se constitui no espaço da Maré e pelas práticas da ELDM, para a reflexão aqui proposta, optamos por desenvolver este texto em primeira pessoa - neste caso, na voz de um dos autores. Tal posicionamento se alinha à pesquisa centrada em sujeitos, defendida por Kilomba (2019, p. 82). De acordo com a autora, esse tipo de investigação examina as experiências e relatos dos sujeitos partindo de suas próprias perspectivas, em vez de tratá-los como um "outro", descrito pelos olhos de alguém que não viveu as mesmas experiências. Enfatizaremos a dimensão corporal na constituição destes sujeitos políticos, sociais e individuais, categorias fundantes de um sujeito, para Kilomba (2019, p. 81).

A pesquisa centrada em sujeitos aproxima, assim, pesquisador/a e pesquisadas/os, pois reúne indivíduos que compartilham experiências e posição social e estão imersos em problemas comuns, o que permite gerar conhecimento a partir de relações de poder menos díspares. Falaremos, a partir, desta perspectiva, de minha aproximação racial e social com estudantes do Núcleo de Formação Intensiva em Dança da ELDM, considerando a importância da autorrepresentação no discurso acadêmico (KILOMBA, 2019, p. 82).

Partiremos de minhas atividades e vivências como professor, buscando indagar como se dá a minha relação com a Maré e com as/os alunas/os da escola e as relações desses/as alunas/os com a cidade, refletindo sobre as marcas do racismo cotidiano que nos atravessam nesses espaços. Para isso, trataremos ainda de algumas experiências desenvolvidas na ELDM, consideradas por nós como práticas corporais críticas e antirracistas.

\section{A Escola Livre de Dança da Maré}


A Escola Livre de Dança da Maré - ELDM funciona dentro do Centro de Artes da Maré - CAM. O CAM é um equipamento cultural, criado pela Lia Rodrigues Companhia de Dança $^{3}$ em parceria com a Redes de Desenvolvimento da Maré, ${ }^{4}$ inaugurado em 2009. O CAM encontra-se na Nova Holanda, umas das dezesseis favelas do Complexo de Favelas da Maré, na cidade do Rio de Janeiro. ${ }^{5}$ Lia Rodrigues chegou na Maré para uma residência artística em 2004 e, desde então, transferiu as atividades de sua companhia para a região, tendo vindo da Zona Sul do Rio de Janeiro, uma das áreas mais abastadas da cidade (SOTER; PAVLOVA, 2017, p. 266). Em 2011, a Escola Livre de Dança da Maré foi inaugurada dentro do espaço do CAM.

A ELDM tem dois núcleos em sua constituição, ambos oferecendo atividades gratuitas para o público em geral: o Núcleo 1, composto por todas as aulas abertas da escola (balé clássico, danças urbanas, dança de salão, dança afro-brasileira, consciência corporal e yoga); e o Núcleo 2, o Núcleo de Formação Intensiva em Dança, que contempla jovens de 14 a 25 anos, selecionadas/os via audição para desenvolverem um trabalho de formação técnica em dança contemporânea em contato estreito, por tempo indeterminado, com a Lia Rodrigues Companhia de Danças. As atividades do Núcleo 2 foram iniciadas em 2012 e mais de sessenta jovens já passaram por este projeto de 2012 a 2019. As aulas do Núcleo 2 acontecem de segunda a sexta-feira, de $14 \mathrm{~h}$ às $17 \mathrm{~h} 30$, e as/os alunas/os recebem uma bolsa auxílio para custear despesas básicas de transporte e alimentação. O intuito do Núcleo 2 é, para além da formação técnica, contribuir na formação de cidadãos por meio da dança. O CAM é um dos raros espaços dedicados à arte em todo o território da Maré, que tem apenas um único equipamento público de cultura, a Lona Cultural Municipal Herbert Vianna, ${ }^{6}$ cogerida pela Redes da Maré.

Minha atuação na ELDM se iniciou em 2016, quando entrei para o quadro de professores regulares da escola, ministrando aulas abertas de dança afro-brasileira, função que exerço até hoje, em 2019. Vejo, nessa ação da escola - que pela primeira vez oferecia aulas regulares de dança afro-brasileira - , uma vontade de trazer pensamento racial a partir de uma prática de dança. Ao longo dos anos, dentro das minhas aulas e ao acompanhar suas repercussões na ELDM, fui percebendo que a construção de discurso racial era uma questão importante também para as/os alunas/os e para a vida dessa escola, com frequência atravessada pela violência em sua face racial. 
De acordo com o Atlas da Violência $2017,{ }^{7}$ a cada 100 pessoas assassinadas no Brasil, 71 são negras. A publicação traz ainda que os negros possuem chances 23,5\% maiores de serem assassinados em relação a brasileiros de outras raças, já descontado o efeito de idade, escolaridade, sexo, estado civil e bairro de residência. No que diz respeito a mortes decorrentes de intervenção policial, o Atlas contabiliza 645 mortes em 2015, sendo o estado do Rio de Janeiro o segundo com maior índice, atrás apenas de São Paulo, com 848 mortes no mesmo ano (Atlas da Violência, 2017, p. 24). Apenas no primeiro semestre de 2019, foram contabilizados 27 homicídios na Maré, ${ }^{8}$ além dos inúmeros casos de violência policial e violações de direitos, que raramente são oficialmente registrados ou entram nas estatísticas.

O desenvolvimento das aulas de dança afro-brasileira, ao se basear em outros imaginários e em distintas concepções de movimento e de construção corporal, tem sido central como ação antirracista junto aos seus participantes. Valorizando corpos pretos por meio da educação e da arte, o ensino de dança afro-brasileira vai de encontro à expectativa gerada pelos dados estatísticos que apontam para o genocídio destes corpos pelo Estado.

Em agosto de 2018, fui convidado a ocupar também o cargo de coordenador da ELDM, passando a acompanhar mais de perto as demais aulas e também as atividades do Núcleo de Formação Intensiva em Dança, contribuindo com a direção da escola e a coordenação do eixo arte e cultura ${ }^{9}$ da Redes da Maré, sem deixar de dar aulas de dança afrobrasileira.

\section{Entendendo-me como sujeito corporal negro}

Compreender-me como um sujeito corporal tem passado por aspectos que dizem respeito a estar no mundo como indivíduo negro, professor dessa escola e artista. Neste processo de construção de identidade se cruzam quem eu sou, quem esperam que eu seja e quem me é permitido ser. Como a experiência da ELDM me ajuda a compreender quais são os limites e as possibilidades de um professor negro em uma sociedade marcada pelo racismo estrutural? Em vários aspectos, minha experiência no Complexo de Favelas da Maré se assemelha ao que vivi em outra favela da cidade do Rio de Janeiro: a Pedreira, na Zona Norte da cidade, onde cresci. 
A presença de grupos civis armados, o descaso das autoridades públicas com o cotidiano dos moradores, o medo das ações policiais que, pelo menos na realidade do meu município, têm um cunho racista - são todas experiências que compartilho em casa e no trabalho. Minhas experiências, assim como os relatos de alunas/os da ELDM, confirmam que as forças da segurança pública em territórios favelados operam dirigidas a um recorte racial demarcado.

As favelas, sejam elas verticais ou não, possuem histórias diferentes e dinâmicas próprias de funcionamento que incidem diretamente nas relações que se estabelecem com quem está dentro e quem adentra um território favelado. Nas favelas cariocas é comum a venda de drogas ilícitas a céu aberto e a livre circulação de civis portando armamento pesado e ilegal. O modo como as pessoas se relacionam com os diferentes grupos civis armados, em muitas situações, assume um caráter indiferente e até blasé, pois esses grupos se tornam parte do cotidiano do indivíduo favelado; isso não significa, entretanto, conivência com as atividades que tais grupos desenvolvem, nem que o medo não esteja presente na vida da população.

Há ainda as questões que dizem respeito ao território das favelas, que têm diferentes formas de ocupação. ${ }^{10}$ No meu caso, moro desde a infância numa favela "no asfalto" — como designamos as partes das favelas que não se localizam em morros e estão próximas de grandes vias de circulação, como é também Nova Holanda, onde se localiza o CAM. No asfalto, a presença de grupos civis armados é, em geral, menor, como também é menos frequente a venda de drogas ilícitas no varejo, via de regra.

Ao longo dos anos, as ocupações de territórios que originam favelas vão gerando distintas arquiteturas, reunindo indivíduos de muitas realidades geográficas e culturais e criando dinâmicas próprias de corpo no espaço. Favelas como o Complexo da Maré, formado por dezesseis comunidades distintas e 140 mil habitantes (REDES DA MARÉ, 2019), têm o tamanho de uma cidade e relações de cidade são ali estabelecidas em diferentes esferas, passando, inclusive, pelo corpo e pela educação do corpo. PaolaBerenstein Jacques (2002, p. 59), acredita que o território da Maré cria uma "ginga" no corpo de quem ali vive.

O espaço em movimento é, ao mesmo tempo, o espaço da ginga e a ginga do espaço. A ginga do espaço está diretamente relacionada à ginga corporal. Percorrer as ruelas e becos das favelas é uma experiência de percepção espacial singular, única; a partir das primeiras quebradas se descobre um ritmo de andar diferente, uma ginga sensual, que o próprio percurso impõe. 
A ginga seria a melhor representação da experiência de se percorrer os meandros de uma favela, desse espaço gingado, que é o oposto mesmo da experiência urbana modernista, sobretudo das ruas retas e monótonas das cidades formais projetadas racionalmente.

A idealização e a visão homogeneizada das favelas, assim como a romantização do movimento dos que vivem em favelas, percebidas nesta descrição, não contemplam a complexidade da experiência dos corpos favelados. Movimento, ginga, cadência. Mas e o medo? E a tensão? Como marcam esses corpos?

Por exemplo, lembro-me de um dos meus primeiros deslocamentos adentrando o território da Maré, minha primeira experiência prática sobre o que se espera de um indivíduo negro e favelado como sujeito corporal ao explorar aquele território. Por três anos, ao ir à Maré para trabalhar, eu só havia frequentado o CAM, que, como estabelecido, se situa na Nova Holanda, uma favela horizontal "no asfalto". Quem vai só até o CAM nem sempre se depara com uma realidade "completa" da Maré, ou mesmo da Nova Holanda, já que este está localizado a menos de cem metros de uma importante via de circulação que dá acesso à favela. Certo dia, convidado a fazer um curso em outro prédio, na sede da Redes de Desenvolvimento da Maré, precisei entrar sozinho na favela, o que é pouco recomendado para quem não está habituada/o com os territórios. Recordo-me do meu choque ao ver os grupos civis armados a poucos metros da via principal que dá acesso à Nova Holanda, a venda de drogas a céu aberto, os bloqueios nas ruas para impedir o acesso da polícia. Senti-me com medo e fisicamente mal com tudo aquilo, pois era muito novo para mim, mesmo que eu também seja um indivíduo favelado. Vivi esse medo e desconforto duas vezes, pois entrei e saí da favela no mesmo dia. Ao sair da favela e chegar na via principal para ir embora, tenso e com medo, deparei-me com uma viatura da polícia. Mais medo. Dois policiais armados com fuzis me pararam, perguntaram de onde eu vinha, onde eu morava, me puseram contra a viatura policial para que eu fosse revistado, tiraram todos os conteúdos da minha mochila. Dizer que eu era professor de dança numa escola em Nova Holanda só serviu para que eles fizessem piadas durante a abordagem. Não havia tanta ginga assim no meu corpo, aparentemente. Após alguns minutos de revista e interrogatório, convencidos, então, de que eu não era um traficante ou mesmo um usuário de drogas, deixaram-me ir, mas não sem deixar marcas em quem eu era. Sem saber, eles deixaram mais uma marca na minha 
construção de sujeito corporal, ressignificando minha percepção de corpo negro, do meu corpo negro.

Fanon (2008) analisou as consequências psicológicas da colonização, tanto para o colonizador quanto para o colonizado, assim como o processo de descolonização, considerando aspectos sociológicos, filosóficos e psiquiátricos. Em sua obra Pele negra, máscaras brancas (2008), o autor se apoia em sua própria experiência para pensar sobre a especificidade das vivências de corpos negros. Em detrimento de indivíduos brancos, os sujeitos negros são "sobredeterminados" pelo exterior, não sendo o sujeito negro "escravo da ideia" (FANON, p. 108) que os outros fazem dele, mas de sua aparição, do seu estar no mundo. Ser negro na favela é, nesse sentido, ser um sujeito cuja aparição se dá pelo corpo. $\mathrm{Na}$ maior parte das vezes, as leituras daquele corpo, quando feitas de fora, desconsideram sua subjetividade e suas potencialidades. Como no episódio narrado, o olhar das forças policiais do Estado sobre nós, negros, se configura como um ato de racismo cotidiano, como propõe Kilomba (2019, p. 78):

O racismo cotidiano refere-se a todo vocabulário, discursos, imagens, gestos, ações e olhares que colocam o sujeito negro e as Pessoas de Cor não só como "Outra/o" - a diferença contra a qual o sujeito branco é medido - mas também como Outridade, isto é, como a personificação dos aspectos reprimidos na sociedade branca. Toda vez que sou colocada como "outra", seja a "outra" indesejada, a "outra" intrusa, a "outra" perigosa, a "outra" violenta, a "outra" passional, seja a "outra" suja, a "outra" excitada, a "outra" selvagem, a "outra" natural, a "outra" desejável ou a "outra" exótica -, estou inevitavelmente experienciando o racismo, pois estou sendo forçada a me tornar a personificação daquilo com o que o sujeito branco não quer ser reconhecido. Eu me torno a/o "Outra/o" da branquitude, não o eu - e, portanto, a mim é negado o direito de existir como igual.

Durante a abordagem, a polícia não perguntou quem eu de fato era, não quis saber se eu era professor ou artista, limitou-se a questionar se eu tinha drogas e se eu era da Maré. Não foi a minha "ginga favelada" que falou mais alto. Ou foi? Ao final, não era pelo que eu poderia ser como sujeito corporal negro, mas somente pela ausência, pelo que eu não sou, ou o que se imagina ter certeza em relação a indivíduos como eu em um território de favela. A aparição de indivíduos negros já traz leituras dadas sobre aqueles corpos, como colocam Fanon (2008, p. 108) e Kilomba (2019, p. 75). Como essa experiência educa meu corpo? 


\section{A Escola Livre de Dança da Maré e a construção de sujeitos corporais}

O episódio narrado se deu em julho de 2018 e, desde então, comecei a me perguntar se e como essas experiências eram também vividas pelas/os estudantes da ELDM. Sou professor licenciado em Dança e ao longo de minha formação inicial em uma Universidade Federal na cidade do Rio de Janeiro, não tive muitas oportunidades de discutir as minhas próprias questões raciais dentro da instituição de ensino onde estive. Hoje, como docente, me parece de extrema importância que o diálogo racial surja em ambientes de ensino formal e não formal, que podem ser muito marcados pelo racismo, ainda que de forma velada. Este diálogo parece-me ainda mais necessário quando estas instituições de ensino estão inseridas em contextos já vistos pelas lentes do racismo, como é o ambiente da favela. Ao aproximar-me das experiências das/os alunas/os, constatei que o relato acima sobre o meu medo da polícia ao entrar e sair da Maré em nada difere de relatos das/os alunas/os da ELDM. Ainda que possamos ter distintas articulações no território da Maré e na escola, somos sujeitos negros no mundo, partilhando referências e experiências, dentre elas, o olhar e a ação das forças de segurança sobre nós. O autorreconhecimento étnico e a nossa formação como sujeitos corporais são atravessados por dimensões que escapam ao nosso controle. Como já afirmava Fanon (2008, p. 104), no mundo branco, o homem de cor encontra dificuldades na elaboração de seu esquema corporal. O conhecimento do corpo é unicamente uma atividade de negação. No caso da ELDM, toda vez que um/a jovem negra/o é impedida/o de entrar na favela ou de nesta circular - por exemplo, para estudar dança - ele/a está tendo seu direito de acesso à arte e ao desenvolvimento corporal negado.

Os relatos das/os estudantes se aproximam de minhas próprias percepções pois estamos lidando com uma sociedade cujo racismo nos coloca a todos, professor e alunas/os, dentro de uma mesma concepção redutora, que nos vê somente como mais um corpo negro.

Kilomba argumenta que o racismo é composto por três elementos entrelaçados (2019, p. 75). O primeiro é a construção de/da diferença, já que a pessoa negra é vista como diferente devido a sua origem racial. O segundo é a hierarquia, que dá diferentes valores a essa diferença, sendo o indivíduo branco considerado o padrão e sempre superior ao indivíduo negro. A hierarquização da diferença gera o preconceito e leva finalmente ao terceiro elemento, "o poder", entendido pela autora como pertencente aos indivíduos brancos, sempre em posição de se colocar como superiores. Os três elementos se acompanham de modo 
histórico, político, social e econômico; É a combinação do preconceito e do poder que forma o racismo (KILOMBA, 2019, p. 76).

Deste modo, entendemos que o racismo influencia, inevitavelmente, as experiências corporais dos alunos da Escola Livre de Dança da Maré, assim como as minhas.

\section{Estratégias da ELDM para uma educação antirracista do corpo}

Junior (2008), a partir dos apontamentos de Cavalleiro (2005), propõe que uma educação antirracista deve ser orientada por algumas atitudes, como: reconhecer a existência do problema racial na sociedade brasileira; considerar a diversidade presente no ambiente escolar e se utilizar dela como forma integradora, encorajando a participação de alunos e alunas; elaborar ações que propiciem o fortalecimento da identidade e autoestima de alunas/os pertencentes a grupos discriminados. Tomando essas orientações como referência, entendemos que uma educação antirracista na ELDM deve se orientar para a desconstrução do estigma racial que afeta as/os alunas/os da escola em função do território da Maré, propondo uma reflexão crítica sobre o racismo e, no âmbito deste trabalho, especificamente em relação com as forças policiais do Estado. Deste modo, as ações da escola visam, como atividade inerente ao aprendizado de arte e da dança, a reflexão sobre o corpo que sofre os efeitos do racismo e que tem suas possibilidades educativas reduzidas em função de um recorte racial no que diz respeito à segurança pública.

Aprofundar as discussões sobre o racismo cotidiano tem sido fundamental para encontrar outros modos de relação destes jovens com seus corpos, com a sua identidade, com a Maré e com o restante da cidade. Em seguida, descreveremos algumas propostas desenvolvidas em 2019 junto aos alunos do Núcleo 2 da ELDM, para além das aulas de dança.

\section{Dançar e circular nas cidades}

A ELDM acredita que, para construção de novas narrativas corporais a partir de um projeto artístico, é imprescindível ampliar o campo de circulação de indivíduos pela(s) cidade(s), incluindo pela Maré, parte integrante da cidade do Rio de Janeiro. 
Ir e vir, o que não é necessariamente problemático para moradores de outras áreas da cidade, tem sido um limite concreto e simbólico em territórios como a Maré, marcados pela violência. De acordo com o Boletim Direito à Segurança Pública na Maré ${ }^{11}$ produzido pelo Eixo de Segurança Pública e Acesso à Justiçada Redes da Maré em 2018, as escolas de educação básica da Maré, onde muitos alunos e alunas do Núcleo 2 estudam ou estudaram, tiveram atividades interrompidas por dez dias devido a conflitos policiais. Em 2019, até o início de setembro, de acordo com o acompanhamento das aulas pela coordenação da ELDM, as aulas foram suspensas por pelo menos cinco dias inteiros em função de operações policiais e a presença das/os alunas/os nas aulas é sempre reduzida quando há confrontos em favelas nos arredores da Nova Holanda, ainda que a escola siga aberta.

Refletir sobre a circulação dos corpos na Maré e nas demais partes da cidade tem sido uma das preocupações da ELDM, como formadora não apenas de futuros artistas, mas de cidadãos. Pensando a partir das práticas da ELDM, acreditamos que as propostas lá desenvolvidas buscam formar "novos cariocas" (SILVA; BARBOSA; FAUSTINI, 2012, p.16). Na concepção dos autores,

Os "novos cariocas" sinalizam uma cidade mobilizada por duas dimensões fundamentais: a estética, como consciência sensível das diferenças humanas, com o devido reconhecimento e legitimação do direito à autenticidade; e a ética, que exige a determinação cotidiana para resistir a que qualquer diferença seja transformada em desigualdade - por razões de gênero, étnicas, etárias, religiosas, de orientação sexual, de condição física e psicológica, social, territorial.

Por meio de propostas que geram diálogos entre práticas de dança e demandas sociais e territoriais, a ELDM estimula que os alunos e alunas que por ali passam desenvolvam meios e habilidades para acessar a totalidade da cidade e, como pontuam os autores Silva, Barbosa e Faustini (2012, p. 12), possam compreender as favelas como parte desta cidade, valorizandoas como territórios de extrema importância na formação de uma área como o Rio de Janeiro. Como iniciativas para a ocupação da Maré e da cidade pelas/os alunas/os, a ELDM propõe visitas a diversos equipamentos culturais da cidade, como museus e teatros, idas a espaços diversos dentro da própria Maré, como a Lona Cultural Herbert Vianna e espaços de ações sociais e educativas dentro da favela, e intercâmbios com outras instituições da cidade e parceiros internacionais. 
A Maré tem localização estratégica no município, pois é margeada por algumas das principais vias rápidas da cidade e muito próxima do Aeroporto Internacional do Rio de Janeiro. Sem contar o fato de que a Maré tem o tamanho e o funcionamento de uma cidade, com dinâmicas potentes de circulação de pessoas, trabalho e renda. ${ }^{12}$ Dessa perspectiva, a favela não é considerada como um problema em si, mas como um território repleto de virtudes, dinâmicas próprias e potencialidades com as quais outras partes da cidade podem aprender.

Sobre o circular pelas cidades e sua conexão com o aprendizado em dança, K.P., aluna formada pelo Núcleo de Formação Intensiva em Dança da ELDM, diz:

Pela Escola, eu pude ir para dois lugares: para a França e para a Suíça. E esses lugares, de alguma forma, eles ajudaram a ampliar a minha visão de mundo. Me fizeram me entender como mulher de uma forma diferente, como brasileira, como alguém que trabalha e vive de arte, como favelada e como negra. Isso tudo, para mim, caminha junto com a dança.

$\mathrm{Na}$ fala de K.P., podemos ver como suas vivências na ELDM suscitam o desenvolvimento de habilidades e meios para que as/os alunas/os possam sentir-se seguras/os e autorizadas/os a circular pelos mais diferentes contextos, o que não é frequente para muitos indivíduos favelados, que não se sentem pertencentes a outros locais da cidade.

\section{Conversas sobre segurança pública e política de drogas}

Como modo de colaborar para o processo de entendimento das possibilidades de corpo, que entendemos não se limitar à prática de dança na ELDM, em 2019 foram realizados alguns encontros das/os alunas/os do Núcleo de Formação Intensiva em Dança, o Núcleo 2, com representantes/pesquisadores do Eixo de Segurança Pública e Acesso à Justiça da Redes da Maré. Os encontros tiveram por objetivo fornecer aos/às jovens ferramentas para uma leitura crítica dos acontecimentos que, muitas vezes, impedem que circulem pela Maré, limitando o seu acesso à arte e à dança. Essas rodas de conversa, dinamizadas por profissionais que atuam com segurança pública na Maré, se somam às aulas de dança propriamente dita, para alargar a compreensão dos modos em que corpos se relacionam com o espaço, tornando-os mais conscientes de sua atuação corporal no mundo. Nesses encontros 
foram apresentados dados sobre segurança pública na Maré e discussões sobre ser jovem e negra/o, assim como provocações para que as/os jovens falassem sobre seus sonhos e objetivos na vida e na arte.

Trago aqui alguns dos relatos gerados nessas conversas, convencido da necessidade de pensar maneiras pelas quais indivíduos ajam como sujeitos em suas realidades sociais (KILOMBA, 2019, p. 74). As realidades sociais de indivíduos negros se assemelham às realidades de indivíduos favelados, de modo geral, na cidade do Rio de Janeiro. Do mesmo modo que Fanon (2008, p. 120) afirma que a luta do negro se assemelha à luta do proletariado, uma vez que o capital simbolizaria o homem branco e a força de trabalho, o homem negro. Acredito que a luta da/o negra/o na favela se assemelha - resguardadas as devidas nuances e proporções - às lutas da população favelada como um todo. Além disso, visto que mais da metade dos alunos do Núcleo 2 é formada por indivíduos negros residentes em territórios populares, as conversas sobre segurança pública têm se mostrado importantes para refletir sobre corpo, raça e antirracismo.

Os extratos a seguir foram produzidos pelos estudantes da ELDM, a partir das discussões suscitadas nos encontros. Destaco, inicialmente, uma produção em específico, que vai ao encontro de meus próprios anseios como educador e indivíduo negro frequentador do território da Maré.

O Rio de Janeiro e suas zonas têm um enorme tráfego de pessoas. Como morador do velho oeste carioca, ou seja, a Zona Oeste do Rio de Janeiro, e dançarino na Escola Livre de Dança da Maré, me vejo transitando por duas diferentes periferias e suas distintas realidades, onde o ponto comum, infelizmente, é a segurança pública precária, que se retrata num triste quadro de abandono social, em que, ao invés de nos sentirmos acolhidos e confortáveis por andarmos na rua por onde passamos, acabamos tomados pelo medo, levando a seguinte pergunta pra si: "Será que eu vou voltar?"

Vivemos no país onde existe a cultura do estupro, a cultura do genocídio, a cultura do machismo, feminicídio e até da homofobia e mesmo assim a arte que retrata relatos reais do cotidiano da favela não é vista ou sequer reconhecida. Jovens estão sendo mortos nas portas de suas casas com uniformes da escola, famílias sendo assassinadas sem ter direito de voz, e onde está o culpado? Quando comprovado que a bala que matou um morador de favela inocente foi de PM "fulano de tal", ele logo se nega, dizendo que não foi ele. Vivemos em uma grande pátria dos incidentes onde ninguém é culpado e onde quem morre vira um número na estática da Anistia Internacional, mais um nome a ser gritado na rua e a estampar um jornal. MORREU MAIS UM NEGRO. 


\section{Depoimento do aluno F.A., produzido a partir dos encontros sobre segurança pública e direito à arte}

Por meio desse relato, vemos que as/os estudantes puderam pensar sobre como a falta de uma boa e eficaz gestão de segurança pública no território da Maré produz impactos sobre o direito da população às artes e, no desdobramento deste trabalho, à produção de outras narrativas de corpo.

Ter alunas/os mobilizadas/os e pensando sobre as questões raciais em diálogo com as questões da segurança pública a partir de suas próprias vivências confirma que aos indivíduos negros é imposta a vivência de práticas racistas e discriminatórias na infância, adolescência, juventude e idade adulta nos mais variados espaços sociais (GOMES; SILVA, 2011, p. 23).

Essa vivência, inscrita pelo racismo desde cedo, deixa marcas profundas na vida de professoras/es negras/os. Passar por episódios de racismo cotidiano na Maré marca o meu corpo e as experiências de racismo que me atravessam modificam minha relação com a cidade. O medo, a ansiedade e o desconforto de circular e permanecer em certos lugares são sentimentos que o racismo inscreve no corpo, que passam a fazer parte do modo com que me relaciono com a cidade.

À luz dessa ideia, entendemos que os processos de formação de sujeitos corporais a partir de vivências de dança na Maré não podem deixar de fora as questões e tensões raciais percebidas pelos jovens neste espaço. Se o racismo tem impacto sobre o autorreconhecimento étnico de professoras negras, como indicam Gomes e Silva (2011), o mesmo se aplica à formação dos estudantes da ELDM.

Um outro depoimento, mais poético, porém distinto do de Berenstein Jacques (2002, p. 59), trata também dos anseios das/os alunas/os do Núcleo 2 sobre o as questões raciais e a segurança pública:

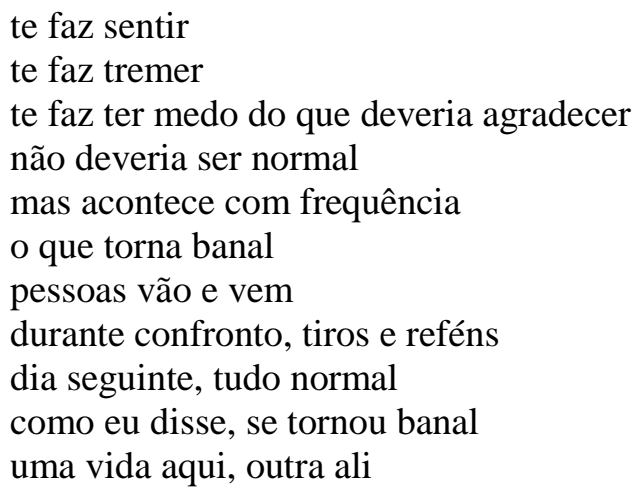


tanto faz, o que importa é EU não me ferir

"seja na favela ou no asfalto"

mas sabemos que é sempre na favela, né?

diz não ter classe, cor

mas sabemos que é sempre o negro e pobre, né?

era para te manter seguro

mas te faz se sentir inseguro

segurança: uma proteção

insegurança: o que nos causa a decepção

\section{Poema da aluna Y.O., produzido a partir dos encontros sobre segurança pública e direito à arte}

Pensando a partir de dor e do medo, a aluna Y.O. traz em seu registro questões de racismo e de segurança pública, mas de modo contrastante da visão de BerensteinJacques (2002, p. 59). Não há romantização na vida prática da favela.

Além das rodas de conversa sobre segurança pública, outras atividades buscaram ampliar a visão dos estudantes sobre suas realidades, como a visita ao Espaço Normal, um outro equipamento da Redes da Maré. O Espaço Normal é o primeiro local de referência sobre drogas em um espaço de favela no Rio de Janeiro e tem como principal objetivo "pautar uma agenda positiva sobre práticas de redução de danos e políticas de cuidado a pessoas que usamcrack, álcool e outras drogas" ${ }^{13}$ O Espaço Normal tem a estrutura de uma casa, onde usuárias/os abusivas/os de drogas podem ir para descansar durante o dia, pegar roupas gratuitamente, tomar banho, preparar refeições e socializar., além de receber atendimento médico, social e jurídico.

A visita a esse equipamento foi seguida de conversa com membros da gestão do espaço, na qual as/os alunas/os do Núcleo 2 puderam aprofundar seu conhecimento sobre assuntos relacionados a políticas de drogas. A ida ao Espaço Normal, para além do acesso a um lugar seguro para a produção e difusão de conhecimento sobre drogas, ajuda as/os alunas/os a entender melhor a dinâmica das drogas na favela, fato que marca de forma muito significativa os territórios e as vidas de todos os habitantes — usuários de droga ou não —, uma vez que, pelo menos na Maré, o tráfico de drogas é um dos maiores fatores geradores de violência policial. Apenas em 2018, foram realizadas dezesseis operações policiais, tendo seis delas durado mais de dez horas, de acordo com o Boletim Direito à Segurança Pública na Maré. O foco da maioria das operações policiais é a busca e apreensão de drogas e armamentos ilícitos, criminosas/os foragidas/os ou cargas roubadas. As operações não 
acontecem sem que haja violência e confrontos entre polícia e grupos civis armados, responsáveis pelo tráfico ilegal de drogas e roubos de cargas. Nessas operações é muito comum que a dinâmica de vida dos moradores seja bastante afetada, pois é muito perigoso sair de casa devido à imprevisibilidade de tiroteios entre polícia e grupos civis armados e disparos dados a partir de helicópteros da polícia sobrevoando a região. Desse modo, as aulas nas escolas são interrompidas, professores/as não chegam à Maré, pessoas não conseguem sair de casa para trabalhar. Às vezes dias inteiros são perdidos na favela em função de operações policiais.

Compreender melhor as dinâmicas de segurança pública e a políticas de drogas tem se mostrado um caminho interessante para uma formação mais ampla de alunas/os do Núcleo 2, uma vez que o território em que vivem e/ou estudam dança é atravessado por essas questões, que acabam por produzir impacto direto nas atividades da ELDM e na vida de cada um/a.

O entendimento das diferenças é parte importante do trabalho de formação do Núcleo 2. Ter pessoas de distintas origens num mesmo espaço, numa favela, dá aos alunos e alunas a chance de viver diferentes nuances da cidade. Gente "de dentro" e "de fora" da Maré, gente de bairros pobres e de bairros ricos, gente preta e gente branca convivem na ELDM e tornam a favela ainda mais cidade, pois as cidades se configuram pela diversidade. Para além da romantização do espaço favelado, a diversidade faz com que esse espaço se torne real em seus limites e potencialidades, que podem ser vivenciados por todas/os que se propõem a estar lá. Esse convívio não é necessariamente fácil, mas é uma prática intencional. Estimular o convívio das diferenças, ainda que possa gerar tensões e conflitos, é uma aposta da ELDM para a construção de uma cidade menos desigual e mais interessante. Como lembra Barbosa (SILVA; BARBOSA; FAUSTINI, 2012, p. 70),

A cidade, dizia Shakespeare, são as pessoas nos seus conflitos, medos, alegrias e paixões. As pessoas, para serem plenas na cidade, precisam das palavras e das ações. Aristóteles considerava o homem um ser dotado da palavra. Segundo ele, a partilha das palavras contribuía para o ser humano aceder da animalidade à civilidade, pois a doxa (opinião) era a expressão própria da construção do ethos comunitário (koínonia) de sujeitos autônomos e coletivos. Essa partilha, que conduzia a constituição do sujeito ético em ação, possuía um lugar próprio: a pólis. A cidade significava, por excelência, o reino da comunicação, da ação e de toda a complexidade social marcada por diferentes protagonistas. Trata-se, portanto, da enunciação de um projeto de tessitura da igualdade e da diferença do 'ser no mundo' como atributo da sociabilidade humana. É desse modo que a utopia da cidade democrática se torna parceira dasperspectivas generosas de humanidade. 
Desse modo, a ELDM se torna um lugar em que se pode falar, ouvir, ceder e estar com o outro na relação diária com as diferenças e as contradições. Isso é importante para a dança. E para a vida. Como confirma o depoimento da aluna J.A.:

Meu nome é J. A., moro em Senador Camará, tenho 21 anos. O Núcleo 2 está me proporcionando uma experiência de troca muito rica, não é apenas um aprimoramento técnico, também é uma vivência de aprendizado em conjunto, como ser parte de um grupo, crescer junto e ser receptiva para aprender com o outro.

O relato da aluna J.A. vai ao encontro das intenções da ELDM de exercitar a leitura da Maré como cidade, entendendo que é composta por diferentes indivíduos com distintas intenções e que a convivência deve ser um exercício que passa pelo corpo. Neste sentido, a escola se propõe a dar espaço para que os todos os indivíduos que por ali passam e que lá participam dos processos educativos possam, como coloca Kilomba (2019, p. 82), ser respeitados em suas esferas política, social e individual, falando por si mesmos e tendo espaço para reflexão e atuação no mundo. Isso é parte do processo de construção de novas/os cariocas, como trazem Silva, Barbosa e Faustini (2012, p. 17):

O novo carioca vive numa cidade em construção de significados generosos, em processo de eliminação das fronteiras territoriais e simbólicas construídas pelas gerações passadas e que tantas dores e sofrimentos ainda provocam. Ele é um ser sem teleologia, que não projeta em futuro indeterminado sua esperança de ser pleno, mas busca viver no cotidiano, a cada dia, a possibilidade de sua humanidade e de sua existência.

A partir das análises feitas neste estudo, pensamos em como uma escola de dança dentro de uma favela carioca pode enfrentar questões cruciais para o desenvolvimento e sobrevivênciade seus alunos e alunas, levando em consideração as demandas sociais do território, tendo suas ações potencializadas por essas questões. Identificamos nos processos da ELDM iniciativas que versam sobre o combate ao estigma das diferenças, em especial as diferenças raciais, e entendemos essas ações como potencializadoras de discursos e de presença das/os alunas/os no mundo. A escola participa, sob essa perspectiva, do desenvolvimento do esquema corporal de seus alunas/os (FANON, 2008, p. 104) e fomenta sua inserção na sociedade como sujeitos que têm suas esferas de subjetividade reconhecidas política, social e individualmente (KILOMBA, 2019, p. 81). 


\section{Considerações finais}

Gomes e Silva (2011, p. 22), ao refletir sobre abordagens pedagógicas relativas à diversidade e à construção das diferentes identidades, alertam que é preciso saber o que pensam professores/as e alunas/os enquanto sujeitos e não só como profissionais, entender como eles/as constroem suas identidades para além dos processos educativos formais. Ao refletir sobre minha experiência e sobre as experiências das/os alunas/os que, como eu, carregam marcas de racismo e violência, constato que, ainda que eu fale do lugar do professor e eles do aluno, somos companheiros de narrativa, já que nos constituímos como sujeitos corporais por meio de embates raciais. Ao cruzar nossos relatos, entendo melhor o meu lugar, percebo em que posições meu próprio corpo me coloca como educador e como coordenador de um projeto de dança e reflito sobre minha prática docente estruturada em conhecimentos que se ancoram no corpo. No meu e nos deles.

Como escola de dança, a ELDM parte de uma perspectiva de arte que quer ser empenhada, militante, engagé, que quer enfrentar os problemas vitais de seu tempo (PAREYSON, 2001, p. 39). Nessa escola, a dança - a arte — é fim e também é meio. Tem sido um caminho para ampliar as possibilidades dos corpos na favela e no restante da cidade.

Kilomba defende a urgência de se valorizar uma epistemologia que contemple sujeitos marginalizados, que incorpore suas experiências, discursos e teorizações. Essas experiências, coloca a autora, espelham as realidades históricas, políticas, sociais e emocionais das 'relações raciais' em espaços acadêmicos e deveriam, portanto, ser articuladas tanto teoricamente quanto metodologicamente (KILOMBA, 2019, p. 58).

As práticas da Escola Livre de Dança da Maré vêm experimentando novas metodologias para estimular a reflexão e alargar o espectro de ação de seus estudantes, estimulando-os a construir novos discursos e novas epistemologias do corpo e do movimento. A criação de espaços para a reflexão e ação sobre questões como o racismo e a violência dentro dos processos pedagógicos tem sido uma estratégia efetiva de educação antirracista para a formação de indivíduos mais conscientes e críticos em relação às questões raciais e sociais às quais estão submetidos. Essas práticas talvez possam servir de exemplo para outras 
situações educativas que queiram considerar a construção de sujeito corporais em seus processos de ensino e aprendizagem.

\section{REFERENCIAS}

Boletim Direito à Segurança Pública na Maré. Redes de Desenvolvimento da Maré. Disponível em <http://redesdamare.org.br/media/downloads/arquivos/BoletimSegPublica2018.final.pdf $>$. Acesso em: 13 jul. 2019.

CAVALLEIRO, E. Discriminação racial e pluralismo em escolas públicas da cidade de São Paulo. In: SECRETARIA DE EDUCAÇÃO CONTINUADA, ALFABETIZAÇÃO E DIVERSIDADE (SECAD). Educação anti-racista: caminhos abertos pela lei federal $\mathbf{n}^{\mathbf{0}}$ 10.639/03. Brasília: Ministério da Educação, Secretaria de Educação Continuada, Alfabetização e Diversidade (MEC-SECAD), 2005. p. 65-104. Disponível em: $<$ http://pronacampo.mec.gov.br/images/pdf/bib_volume2_educacao_anti_racista_caminhos_a bertos_pela_lei_federal_10639_2003.pdf>. Acesso em: 2 out. 2019.

FANON, F. Pele negra, máscaras brancas. Trad. Renato da Silveira. Salvador: EDUFBA, 2008.

JUNIOR, W. E. F.Educação anti-racista: reflexões e contribuições possíveis do ensino de ciências e de alguns pensadores. Disponível em: $\langle$ http://www.scielo.br/scielo.php?script=sci_arttext\&pid=S1516-73132008000300003 $>$. Acesso em: 2 out. 2019.

KILOMBA, G. Memórias da plantação - episódios de racismo cotidiano. Rio de Janeiro: Cobogó, 2019.

GOMES, N.L.; SILVA, P.B.G.(orgs.) Experiências étnico-culturais para a formação de professores. 3 ed. Belo Horizonte: Autêntica, 2011. (Coleção Cultura Negra e Identidades.)

PAREYSON, L. Os problemas da estética. Trad. Maria Helena Nery Garcez. 3 ed. São Paulo: Martins Fontes, 2001.

REDES DA MARÉ (org.). Censo Populacional da Maré. Rio de Janeiro: Redes da Maré, 2018.

SILVA, J. S.; BARBOSA, J. L.; FAUSTINI, M. V. O novo carioca. Rio de Janeiro: Mórula Editora, 2012.

SOTER, S. C. S.; PAVLOVA, A. Escola Livre de Dança da Maré: a ground to share. In: BUTTERWORTH, J.; WILDSCHUT, L. (org.). Contemporary Choreography. 2 ed.Londres: Routledge, 2017, v. 1, p. 1-480. 


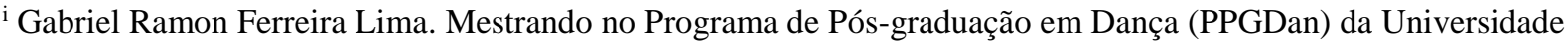
Federal do Rio de Janeiro (UFRJ). E-mail: gabrielrflima@gmail.com. https://orcid.org/0000-0003-4655-5039.

iiSilvia Camara Soter da Silveira. Professora Adjunta da Faculdade de Educação e Programa de Pós-graduação em Dança (PPGDan) da Universidade Federal do Rio de Janeiro (UFRJ). E-mail: ssotersilvia @ gmail.com. https://orcid.org/0000-0002-9760-8551.

3““ A Lia Rodrigues Companhia de Danças foi fundada por Lia Rodrigues em 1990, no Rio de Janeiro. Em 2003, a Lia Rodrigues Companhia de Danças foi convidada por SilviaSoter para colaborar com a Redes de Desenvolvimento da Maré, no Morro do Timbau, para onde transferiu suas atividades diárias, ajudando a construir e garantir a manutenção de local adequado para a dança, além de oferecer aulas e oficinas para jovens da comunidade e doar um grande acervo de vídeos de dança e livros. [...] Em 2007, a Companhia, sempre em parceria com a Redes da Maré, iniciou um novo projeto na comunidade da Nova Holanda, na Maré. A criação do Centro de Artes da Maré, um lugar de partilha, convivência e de troca de saberes, direcionado para a formação, criação, difusão e produção das artes. O CAM, além de ser a sede da Lia Rodrigues Companhia de Danças, abriga entre outras iniciativas a Escola Livre de Dança da Maré." Disponível em 〈http://www.liarodrigues.com/page2/styled-2/index.html>. Acesso em: 13 jul. 2019.

4“'A Redes da Maré é uma instituição da sociedade civil que produz conhecimento, elabora projetos e ações para garantir políticas públicas efetivas que melhorem a vida dos 137 mil moradores das 16 favelas da Maré. [...] O processo que gerou a criação da Redes da Maré começou em 1997, a partir da iniciativa de moradores e exmoradores oriundos de algumas das 16 favelas que formam a Maré e de outras partes da cidade do Rio de Janeiro. [...] A primeira iniciativa elaborada pelos fundadores da Redes da Maré foi o projeto de preparação aos exames de acesso à universidade, o Curso Pré-Vestibular Comunitário da Maré." Disponível em 〈https://redesdamare.org.br/br/quemsomos/historia〉. Acesso em: 13 jul. de 2019.

${ }^{5}$ De acordo com o Censo Populacional da Maré (2019), realizado pela Redes da Maré, o Complexo de Favelas da Maré conta com aproximadamente 139.073 moradores em dezesseis diferentes favelas.

6“"Em 2009, a Redes da Maré assumiu a cogestão da Lona Cultural Municipal Herbert Vianna, numa parceria com a Secretaria Municipal de Cultura, e desde então o espaço consolidou-se ainda mais como palco referência de arte e lazer na região, enquanto foi se tornando também local de formação e aprendizagem. No encontro das comunidades Baixa do Sapateiro, Nova Holanda e Nova Maré, a Lona Herbert Vianna pulsa mais viva do que nunca, atraindo moradores de diferentes áreas e derrubando barreiras invisíveis, porém concretas de circulação. A programação gratuita, que atrai cerca de 5 mil pessoas por ano, é variada: há os tradicionais shows, que vão do rock ao metal, mas também roda de samba, forró, bloco de carnaval, mostra de cinema, cineclube, espetáculo infantis, de teatro e musicais. A Biblioteca Popular Municipal Jorge Amado funciona como ponto de encontro de leitores, enquanto crianças e adultos têm a chance de fazer aulas ou oficinas variadas como letramento, música, robótica, dança, culinária, formação de mão de obra para eventos culturais ou até mesmo participar de um projeto de educação ambiental." Disponível em <http://redesdamare.org.br/br/info/4/lona-cultural-municipal-herbertvianna>. Acesso em: 2 de out. 2019.

$\begin{array}{lllll}7 & \text { datlas } & \text { Violência } & 2017 . & \text { Disponível }\end{array}$

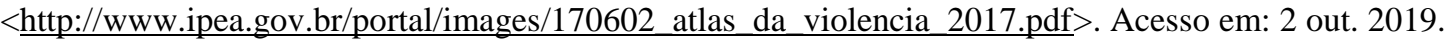

${ }^{8}$ Dados disponíveis em: <https://oglobo.globo.com/opiniao/violencia-faz-favela-ficar-doente23896970?fbclid=IwAR1CNjNCzBIblUOKo7ADzmKknYtYzZ1EzX--J4-mNVhJYS2blPINRx2HNy4>. Acesso em: 2 out. 2019.

${ }^{9}$ A Redes de Desenvolvimento da Maré é uma organização da sociedade civil que possui cinco eixos de atuação que são considerados estruturantes de suas atividades no território da Maré: Arte e Cultura, Desenvolvimento Territorial, Educação, Identidades e Memória e Direito à Segurança Pública e Acesso à Justiça. 
${ }^{10}$ Para mais informações sobre a favela da Nova Holanda, consultar Memória e identidade dos moradores de Nova Holanda. Disponível em: <http://redesdamare.org.br/media/livros/memoria-identidade-moradores-novaholanda.pdf $>$. Acesso em: 2 out. 2019.

${ }^{11}$ Disponível em: <http://redesdamare.org.br/media/downloads/arquivos/BoletimSegPublica2018.final.pdf $>$. Acesso em: 2 out. 2019.

${ }^{12}$ Para mais detalhes, consultar o Censo de empreendimentos Maré. Disponível em: <http://mareonline.com.br/wp-content/uploads/2019/05/Censo_Empreendimentos_24_julho.pdf >. Acesso em: 2 out. 2019.

${ }^{13}$ Informações disponíveis em: 〈http://redesdamare.org.br/br/info/14/espaco-normal〉. Acesso em: 2 out. 2019. 